\title{
MODELING OF 21 JULY 2017 GEOMAGNETIC STORM
}

\author{
Emre Eroglu \\ Department of Mathematical Research, Armoya High Technology Institute, Turkey \\ eroglumre@gmail.com
}

\begin{abstract}
This essay involves mathematical analyzes of 21 July 21, 2017, geomagnetic storm in the $24^{\text {th }}$ solar cycle. It focuses on solar wind parameters $\left(\mathrm{B}_{\mathrm{z}}, \mathrm{E}, \mathrm{P}, \mathrm{N}, \mathrm{v}, \mathrm{T}\right)$, zonal geomagnetic indices (Dst, ap, $\mathrm{AE}$, $\mathrm{Kp}$ ) obtained from NASA and discusses the July storm by strictly obeying the cause-effect relationship. The paper examines the phenomenon carefully and tries to reveal properties of the storm with the models governing by the causality principle. In this study, values interval and deviations of the variables are defined via descriptive analysis, binary relationships of the data are displayed with the covariance matrix and the cluster of the data are introduced by the dendrogram. Factor analysis is conducted with the help of normal distributions of the data and the phenomenon is tried to discuss with linear and nonlinear models. The study, without detachment from the context of the discussion, also detects anomalies of total electron content (TEC) data obtained from CODE (GIM).
\end{abstract}

Keywords: Mathematical modeling, zonal geomagnetic indices, solar wind parameters

\section{Introduction}

The geomagnetic storms observed from the earth generally initiate with a substantial change in the magnitude of the magnetic field with a solar wind, which is the dynamic standard of the polarized proton-electron [29], a burst that ruptures from the sun. A geomagnetic storm has three phases: 1 . Sudden commencement, 2. The main phase and 3. The recovery phase. The first pulse (sudden commencement) are related with a peak in dynamic pressure [3,7]. The peak in dynamic pressure creates hydrodynamics shocks toward the interplanetary environment with the solar wind. Any shock from the disturbance in the magnetic field does not have to be followed by a storm. A geomagnetic storm occurs when the coronal mass ejection (CME) cloud swallows the magnetosphere of the earth and the $\mathrm{B}_{\mathrm{z}}$ component of the magnetic field is oriented in a negative direction (southward). The stimulating proton-electron detach from the sun, the isotopes of light in the solar corona, and the plasmas scatter through the solar magnetic field. These electrons-protons relate with the magnetic field of the earth and cause a disturbance in the magnetosphere and the ionosphere [14,26,30,34]. During the storm, the plasma and particles 
are dispersed throughout the solar corona via the magnetic field with waves of linearly polarized magneto sonic [15]. The CME with a dynamic structure has the ability to change and shape the solar wind parameters [17]. In the course of the CME burst, the plasma clouds with very high velocities scatter to govern the zonal geomagnetic indices that influence the magnetosphere. The effects of the geomagnetic storm are explained by magnetic activity indexes such as AE (auroral electrojet), ap, Kp (planetary index) and Dst (Disturbance Storm Time) [8,23,24,27]. The author utilizes Dst, AE, ap and semi-logarithmic Kp indices hourly. As many scientists have done, the author tries to comprehend and interpret the weak storm of July 21, 2017, by focusing on solar wind parameters and zonal geomagnetic indices.

The time-response times of weak storms are almost half the time-response times of intense storms. In an intense storm, the solar wind parameters have enough time to react, but weak storms do not have such a facility. They have to react quickly. In this paper, 21 July 2017 weak geomagnetic storm (Dst $=-33$ ) is analyzed in a mathematical discipline, and is modeled with proven $[12,13,22]$ models in moderate and severe storms are made. Throughout the study, the cause-effect relationship governs all mathematical approaches and the author obeys to the causality principle [9-11]. The study models and visualizes in addition to gives the opportunity to compare correspondence data. The author also utilizes TEC data obtained from GIM published Center for Orbit Determination in Europe (CODE). These data are included in the variables-set such as solar wind parameters and zonal geomagnetic indices in all analyzes. The study questions the relationship between the ionosphere and the terrestrial globe through anomalies of TEC values [20-22,33].

In Section 2 solar parameters, zonal geomagnetic indices and five-day distributions of data are presented. In Section 3 the analyses are completed. In Section 4 a discussion is contends.

\section{Data}

IDL-Based data is utilized from Space Physics Environment Data Analysis Software (SPEDAS). Geomagnetic classification [25] is in the below Table 1.

Table 1. Geomagnetic storm Dst index

\begin{tabular}{|c|c|c|c|c|}
\hline Class & Number & $\%$ & \multicolumn{2}{|c|}{ Dst Range (nT) } \\
\hline Weak & 482 & 44 & -30 & $-\quad-50$ \\
\hline Moderate & 346 & 32 & -50 & $-\quad-100$ \\
\hline Strong (i.e., intense) & 206 & 19 & -100 & $-\quad-200$ \\
\hline Severe (very-intense) & 45 & 4 & -200 & $-\quad-350$ \\
\hline Great & 6 & 1 & $<$ & -350 \\
\hline
\end{tabular}

For discussion of the weak storm 21 July 2017 the magnetic field, electric field, solar wind dynamic pressure, flow speed, proton density, and temperature are utilized from OMNI hourly data. Figure 1 displays the OMNI data set from 00:00 UT on 19 July 2017 to 00:00 UT on 23 July 2017. The plot margin covers the storm day (2017 July 21), two days before and two days after the storm (120 hours). Towards the middle of July 20, when the solar medium is quiet and the solar wind flow speed is between $380 \mathrm{~km} / \mathrm{s}$ and $385 \mathrm{~km} / \mathrm{s}$, within a few hours, the dynamic pressure hits $4.76 \mathrm{nPa}$ and the proton density reaches $16.61 / \mathrm{cm}^{3}$ their peak values. The July storm initiates on July $20^{\text {th }}$ with first CME between 18:00 UT and suddenly the magnetic field component $\left(\mathrm{B}_{\mathrm{z}}\right)$ reaches one of the minimum values of $-4.4 \mathrm{nT}$ by orienting southwards. After 
that the second CME hits at 01:00 UT on 21 July 2017; suddenly the magnetic field component $\left(\mathrm{B}_{\mathrm{z}}\right)$ reaches its minimum value of $-5.6 \mathrm{nT}$, electric field $(\mathrm{E})$ hits its maximum value $2.9 \mathrm{nT}$, the geomagnetic aurora electrojet index (AE) increases one of the its maximum values of $793 \mathrm{nT}$ and then immediately Dst catches its minimum value of $-33 \mathrm{nT}$ at 02:00 UT. Traditionally, the response time of a weak storm is very short

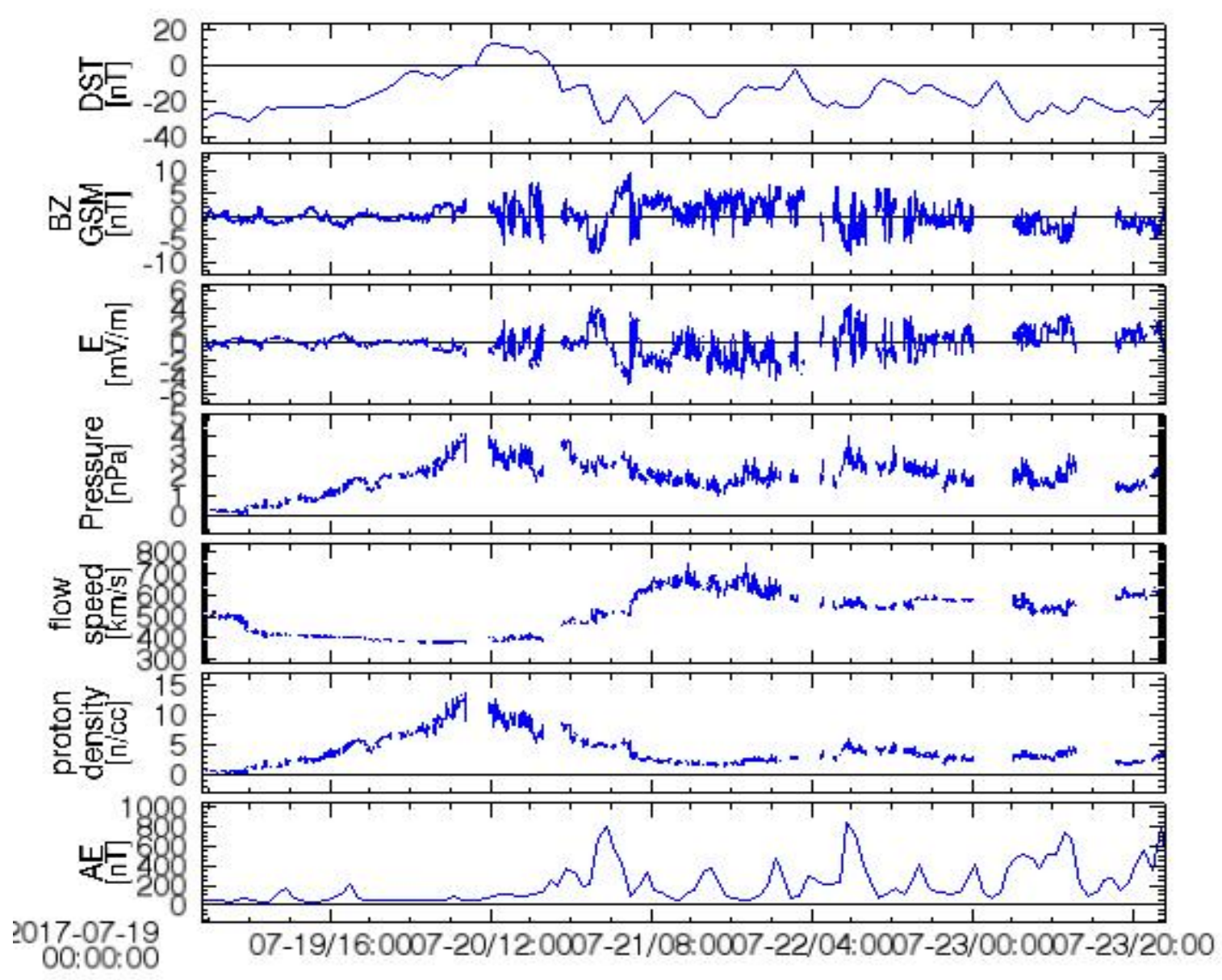

Figure 1. From top of to bottom parameters exhibited in Dst index, $B_{z}$ magnetic field (nT), E electric field $(\mathrm{mV} / \mathrm{m})$, solar wind dynamic pressure $\mathrm{P}(\mathrm{nPa})$, flow speed $\mathrm{v}(\mathrm{km} / \mathrm{s})$, proton density $\mathrm{N}\left(1 / \mathrm{cm}^{3}\right)$, and aurora electrojet AE (nT) index for 2017 July 19-23 (from NASA NSSDC OMNI data set)

The apparatuses of Figure 1 may be momentarily labeled as tracks. On 21.07.2017 at 01:00 UT when $B_{z}$ component is at its minimum (-5.6 nT), Dst index dwindles to -21 nT (hits its peak values of -33 nT at 02:00 UT), the electric field E grasps to its maximum value of $2.9 \mathrm{mV} / \mathrm{m}$. Meanwhile, ap index reaches $22 \mathrm{nT}$, proton density $\mathrm{N}$ reaches $5.21 / \mathrm{cm} 3$, plasma flow speed $\mathrm{v}$ catches $517 \mathrm{~km} / \mathrm{s}, \mathrm{AE}$ index clasps $672 \mathrm{nT}$. After eleven hours flow speed shows its maximum values of $715 \mathrm{~km} / \mathrm{s}$.

On 21.07.2017 at 02:00 UT when Dst index indicates its minimum value - $33 \mathrm{nT}, \mathrm{B}_{\mathrm{z}}$ component increases $-0.3 \mathrm{nT}$, the electric field $\mathrm{E}$ reaches $0.16 \mathrm{mV} / \mathrm{m}$, AE index grasps $793 \mathrm{nT}$, ap index 
shows $22 \mathrm{nT}$ and flow pressure $\mathrm{P}$ takes $2.5 \mathrm{nPa}$.

On 21.07.2017 at 04:00 UT when $\mathrm{B}_{\mathrm{z}}$ component is maximum (5.9 nT), the electric field reaches its minimum value of $-3.07 \mathrm{mV} / \mathrm{m}$, proton density $\mathrm{N}$ takes $5.41 / \mathrm{cm} 3$, AE index diminutions $431 \mathrm{nT}$ and ap index continues to diminution. As this happens Dst index scopes -21 nT.

\section{Mathematical modeling}

For the variables of the July geomagnetic storm, descriptive analysis is demonstrated in Table 2 , and the correlation matrix is in Table 3 . The descriptive analysis shows the change interval, standard deviation, and variance of the data. As the standard deviation value increases, the instability of the variables rises and the possibility of intervention it's to the event decreases. Statistically, the strongest variables are expected to be P, E, $B_{z}$, TEC, N, ap, respectively (Table 2). The mathematical models in which these variables are included are expected to be the maximum useful in explaining the event, provided that the cause-effect relationship is considered. The Pearson matrix indicates the instant relation of the data and the asset of their dual relations. When the values in Table 3 close to \pm 1 , the binary relationships strengthen. Physically, in this storm, $\mathrm{P}$, Dst and $\mathrm{T}$, and $\mathrm{B}_{\mathrm{z}}$ may be more considered with $\mathrm{P}, \mathrm{Kp}$, ap, $\mathrm{v}$ and $\mathrm{N}$ and $\mathrm{P}$ and $\mathrm{v}$ with Kp, Dst, AE, and p. Especially, serious remarkable binary agreement here is between $\mathrm{v}$ and Dst. We are going to support this pact with a nonlinear mathematical model via Table 3.

Table 2. Descriptive analysis

\begin{tabular}{lcccccc}
\hline & $\mathrm{N}$ & Minimum & Maximum & Mean & Median & Std. Deviation \\
\hline $\mathrm{B}_{\mathrm{z}}(\mathrm{nT})$ & 120 & -5.6 & 5.9 & .217 & .2 & 1.9864 \\
$\mathrm{~T}(\mathrm{~K})$ & 120 & 13315 & 564511 & 153787.78 & 162575.5 & 105196.578 \\
$\mathrm{~N}\left(1 / \mathrm{cm}^{3}\right)$ & 120 & .3 & 16.6 & 4.292 & 3.4 & 3.1387 \\
$\mathrm{v}(\mathrm{km} / \mathrm{s})$ & 120 & 381 & 715 & 520.41 & 551 & 93.418 \\
$\mathrm{P}(\mathrm{nPa})$ & 120 & .14 & 4.76 & 1.9878 & 1.94 & .91097 \\
$\mathrm{E}(\mathrm{mV} / \mathrm{m})$ & 120 & -3.07 & 2.9 & -.1314 & -.09 & 1.08999 \\
$\mathrm{Kp}$ & 120 & 3 & 43 & 20.38 & 23 & 11.285 \\
$\mathrm{Dst}(\mathrm{nT})$ & 120 & -33 & 12 & -16.72 & -19 & 10.772 \\
$\mathrm{ap}(\mathrm{nT})$ & 120 & 2 & 32 & 9.93 & 9 & 7.675 \\
$\mathrm{AE}(\mathrm{nT})$ & 120 & 22 & 839 & 208.03 & 131.5 & 193.925 \\
$\mathrm{TEC}$ & 120 & 12.4 & 26.8 & 16.900 & 16.4 & 2.7580 \\
\hline
\end{tabular}


Table 3. Pearson's correlation matrix for the storm variables

\begin{tabular}{|c|c|c|c|c|c|c|c|c|c|c|c|}
\hline & $\mathrm{B}_{\mathrm{z}}(\mathrm{nT})$ & $\mathrm{T}(\mathrm{K})$ & $\mathrm{N}\left(1 / \mathrm{cm}^{3}\right)$ & $\mathrm{v}(\mathrm{km} / \mathrm{s})$ & $\mathrm{P}(\mathrm{nPa})$ & $\mathrm{E}(\mathrm{mV} / \mathrm{m})$ & Kp & Dst(nT) & ap(nT) & $\mathrm{AE}(\mathrm{nT})$ & TEC \\
\hline$\overline{\mathrm{B}_{\mathrm{z}}(\mathrm{nT})}$ & 1 & $.212^{*}$ & .047 & .101 & -.009 & $-.989^{* *}$ & -.149 & .133 & -.170 & $-.313^{* *}$ & .013 \\
\hline $\mathrm{T}(\mathrm{K})$ & & 1 & $-.456^{* *}$ & $.858^{* *}$ & -.027 & $-.270^{* *}$ & $.500^{* *}$ & $-.199^{*}$ & $.362^{* *}$ & $.211^{*}$ & .066 \\
\hline $\mathrm{N}\left(1 / \mathrm{cm}^{3}\right)$ & & & 1 & $-.612^{* *}$ & $.784^{* *}$ & .014 & -.152 & $.798^{* *}$ & -.118 & -.148 & $-.183^{*}$ \\
\hline $\mathrm{v}(\mathrm{km} / \mathrm{s})$ & & & & 1 & -.094 & -.146 & $.581^{* *}$ & $-.399^{* *}$ & $.435^{* *}$ & $.364^{* *}$ & .132 \\
\hline $\mathrm{P}(\mathrm{nPa})$ & & & & & 1 & .049 & $.352^{* *}$ & $.677^{* *}$ & $.294^{* *}$ & $.190^{*}$ & $-.183^{*}$ \\
\hline $\mathrm{E}(\mathrm{mV} / \mathrm{m})$ & & & & & & 1 & .121 & -.102 & .151 & $.309^{* *}$ & -.020 \\
\hline Kp & & & & & & & 1 & -.151 & $.937^{* *}$ & $.676^{* *}$ & -.045 \\
\hline Dst(nT) & & & & & & & & 1 & $-.198^{*}$ & $-.366^{* *}$ & $-.206^{*}$ \\
\hline ap(nT) & & & & & & & & & 1 & $.644^{* *}$ & -.003 \\
\hline $\mathrm{AE}(\mathrm{nT})$ & & & & & & & & & & 1 & -.007 \\
\hline TEC & & & & & & & & & & & 1 \\
\hline
\end{tabular}

KMO and Bartlett's Test investigates the circulation of variables and its appropriateness for factor analysis. In a natural event, because the data are scattered freely, it explains how the data should be coordinated with the event. The data interacting with normal distribution can be modeled by the aid of factor analysis. According to Table 4, the data of the July storm may be demonstrated via the normal distribution.

Table 4. KMO and Bartlett's test

\begin{tabular}{lcc}
\hline Kaiser-Meyer-Olkin Measure of Sampling Adequacy. & .620 \\
\hline \multirow{3}{*}{ Bartlett's Test of Sphericity } & Approx. Chi-Square & 1590.700 \\
& df & 55 \\
& Sig. & .000 \\
\hline
\end{tabular}

Hierarchical cluster discussion of the data of the storm is specified in Figure 2. In this way, there are two main blocks. The first heap is $\mathrm{P}, \mathrm{E}, \mathrm{B}_{\mathrm{z}}, \mathrm{N}, \mathrm{Kp}$, ap, Dst, v, AE, while the second heap contains of temperature $(\mathrm{T})$. 


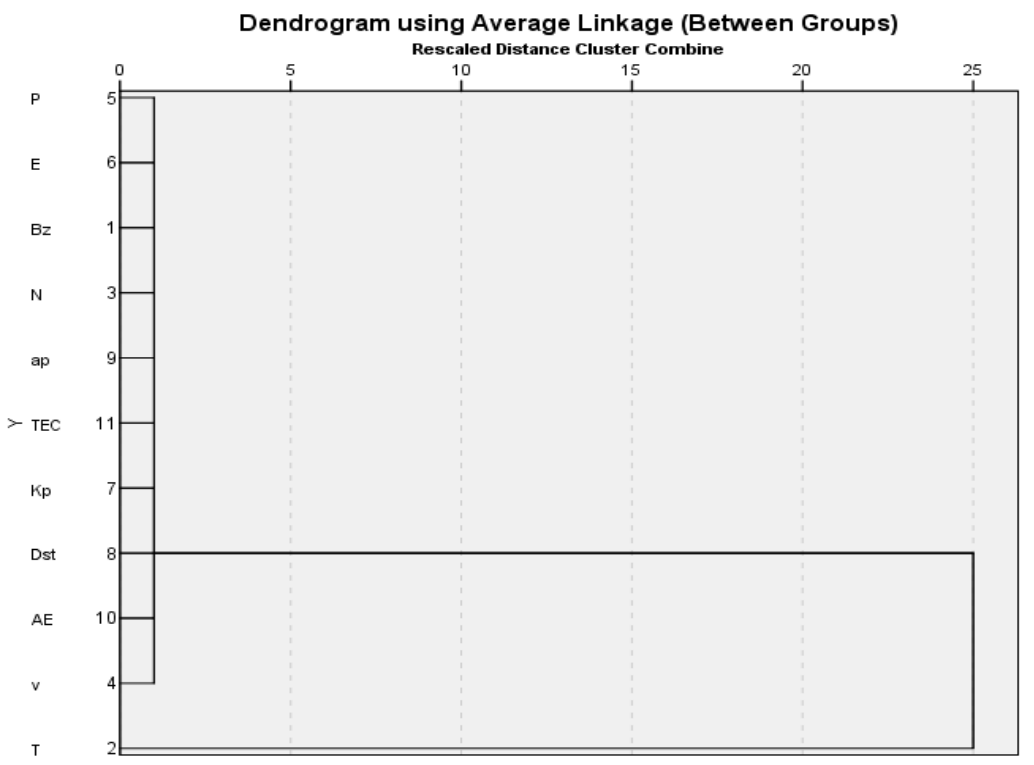

Figure 2. Dendrogram of hierarchical cluster analysis

Kaiser Normalization and Principal Component Analysis is an appropriate analysis for separating variables into subcategory. The data separated into sub-groups show maximum eigenvalues with highest contribution approach. According to Table 5, 77\% of the change (evolution) of the phenomenon with three maximum eigenvalues can be modeled and presented to the reader.

Table 5. Total variance explained

\begin{tabular}{ccccccc}
\hline \multirow{2}{*}{ Component } & \multicolumn{3}{c}{ Initial Eigenvalues } & \multicolumn{3}{c}{ Rotation Sums of Squared Loadings } \\
\cline { 2 - 7 } & Total & $\begin{array}{c}\text { \% of } \\
\text { Variance }\end{array}$ & $\begin{array}{c}\text { Cumulative } \\
\text { \% }\end{array}$ & Total & \% of Variance & Cumulative \% \\
\hline 1 & 3.716 & 33.778 & 33.778 & 3.430 & 31.185 & 31.185 \\
2 & 2.644 & 24.034 & 57.812 & 2.816 & 25.601 & 56.786 \\
3 & 2.201 & 20.013 & $\mathbf{7 7 . 8 2 5}$ & 2.314 & 21.039 & 77.825 \\
\hline
\end{tabular}

Scattering plot of these variables is shown in Figure 3. Figure 3 is displayed all variables in rotated space and is ranked from the maximum between the three variables, with the showing a factor between every two points (right side). 

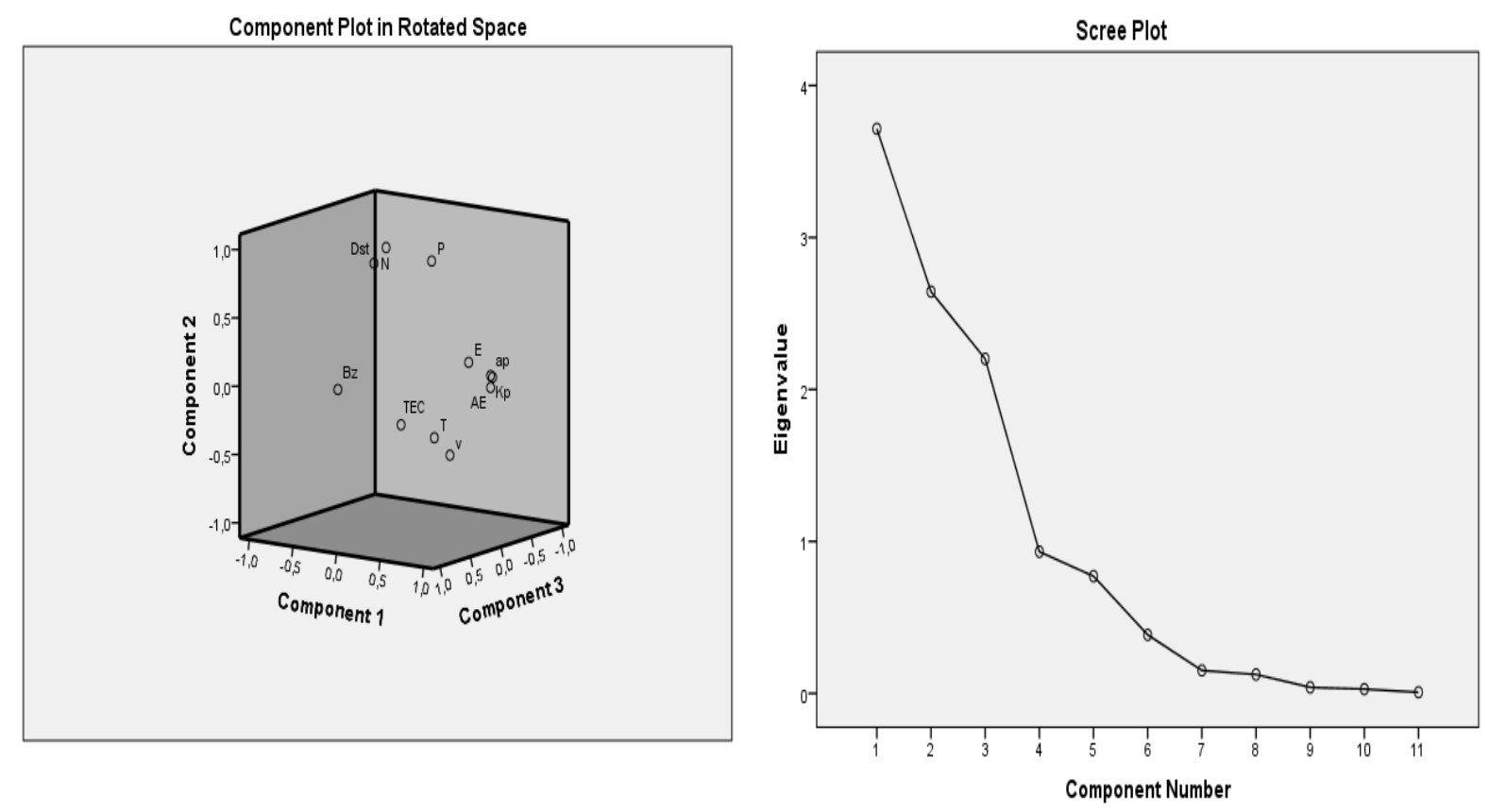

Figure 3. Component plot in rotated space and scree plot for three eigenvalues, respectively.

Varimax Rotation Matrix method examines the linear clustering of variables. The coefficients in Table 6 are the values of the weighted contributions of the variables (factors). It is probable to realize two main axes of the total variance in Table 6 . This table is the weight rotated matrix of the variables given in $77 \%$ total variance.

Table 6. Rotated component matrix

\begin{tabular}{cccccccccccc}
\hline Component & $\mathrm{B}_{\mathrm{z}}(\mathrm{nT})$ & $\mathrm{T}(\mathrm{K})$ & $\mathrm{N}\left(1 / \mathrm{cm}^{3}\right)$ & $\mathrm{v}(\mathrm{km} / \mathrm{s})$ & $\mathrm{P}(\mathrm{nPa})$ & $\mathrm{E}(\mathrm{mV} / \mathrm{m})$ & $\mathrm{Kp}$ & $\mathrm{Dst}(\mathrm{nT})$ & $\mathrm{ap}(\mathrm{nT})$ & $\mathrm{AE}(\mathrm{nT})$ & $\mathrm{TEC}$ \\
\hline 1 & -.100 & .664 & -.241 & .737 & .313 & .069 & .956 & -.228 & .881 & .730 & -0.16 \\
2 & .054 & -.293 & .935 & -.435 & .899 & -.005 & .101 & .853 & .095 & -.038 & -.328 \\
\hline
\end{tabular}

The models that arise with the weights of the data offered in Table 6 are as follows:

Axes $1=-(0.100) \mathrm{B}_{\mathrm{z}}+(0.664) \mathrm{T}-(0.241) \mathrm{N}+(0.737) \mathrm{v}+(0.313) \mathrm{P}+(0.069) \mathrm{E}$

Axes $\begin{aligned} 2= & (0.054) \mathrm{B}_{\mathrm{z}}-(0.293) \mathrm{T}+(0.935) \mathrm{N}-(0.435) \mathrm{v}+(0.899) \mathrm{P}-(0.005) \mathrm{E} \\ & +(0.101) \mathrm{Kp}+(0.853) \mathrm{Dst}+(0.095) \mathrm{ap}-(0.038) \mathrm{AE}-(0.238) \mathrm{TEC}\end{aligned}$

Figure 4a, 4b, and 4c visualize the physical scattering of zonal geomagnetic indices according to parameters. Figure 4 shows the distributions of Dst, $\mathrm{AE}$ and ap indices on $\mathrm{B}_{\mathrm{z}}, \mathrm{E}, \mathrm{T}, \mathrm{v}, \mathrm{N}, \mathrm{P}$. Figures $4 \mathrm{a}, \mathrm{b}$, c help for visualizing of scattering of solar wind parameters 

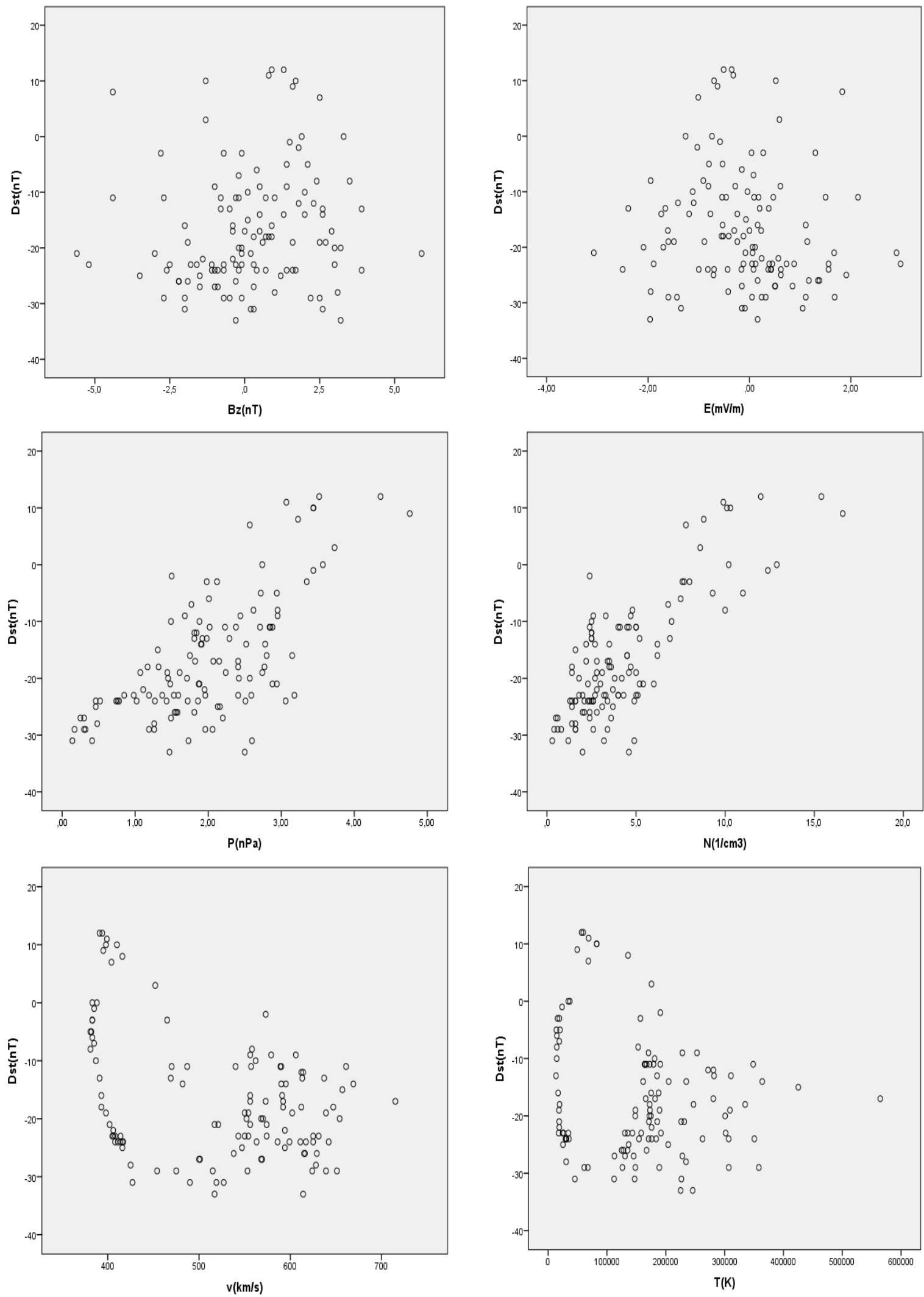

Figure 4a. Scattering of solar wind parameters $B_{z}, E, P, N, v$, T vs. Dst. 

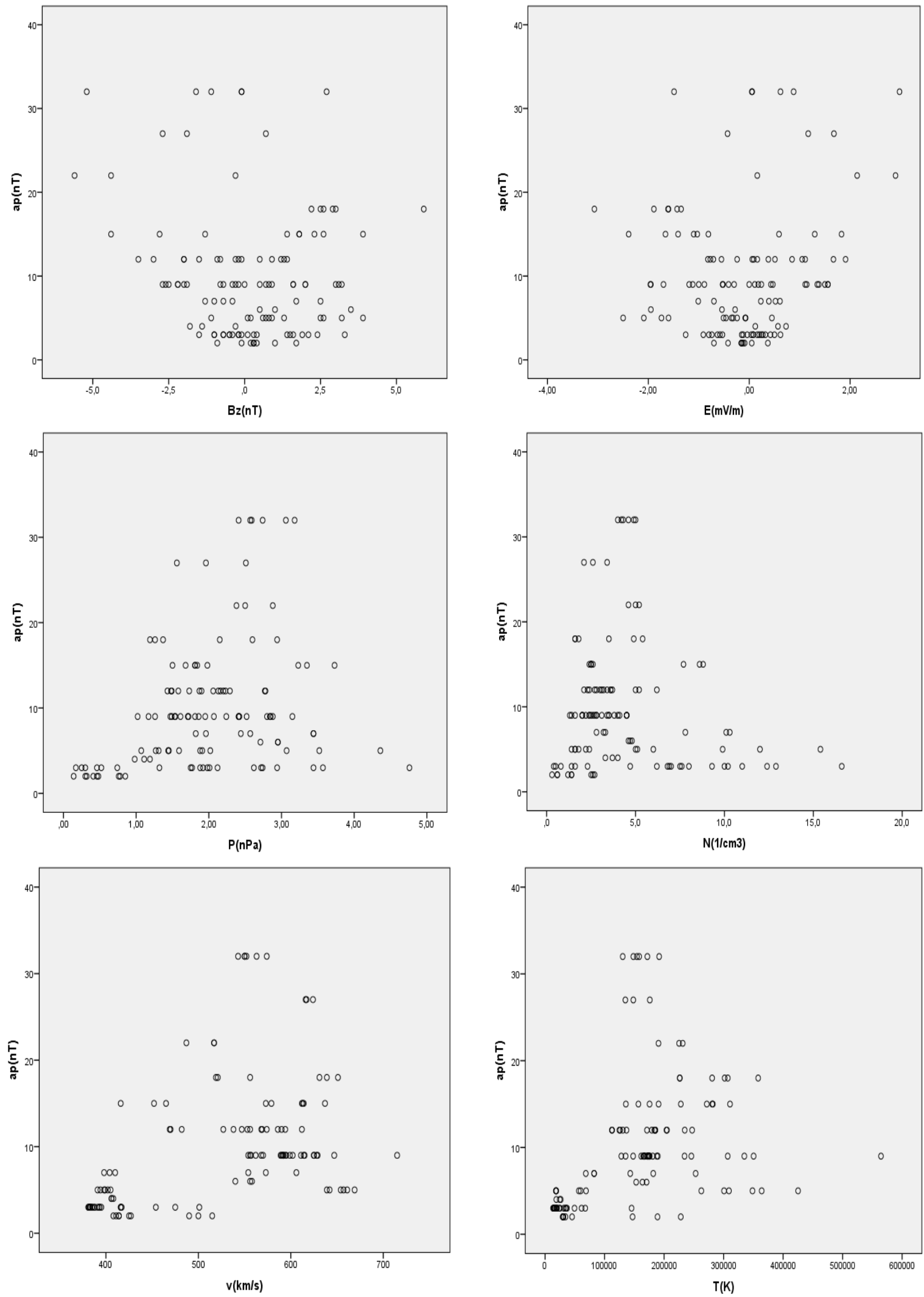

Figure $4 \mathbf{b}$. Scattering of solar wind parameters $B_{z}, E, P, N, v, T$ vs. ap. 

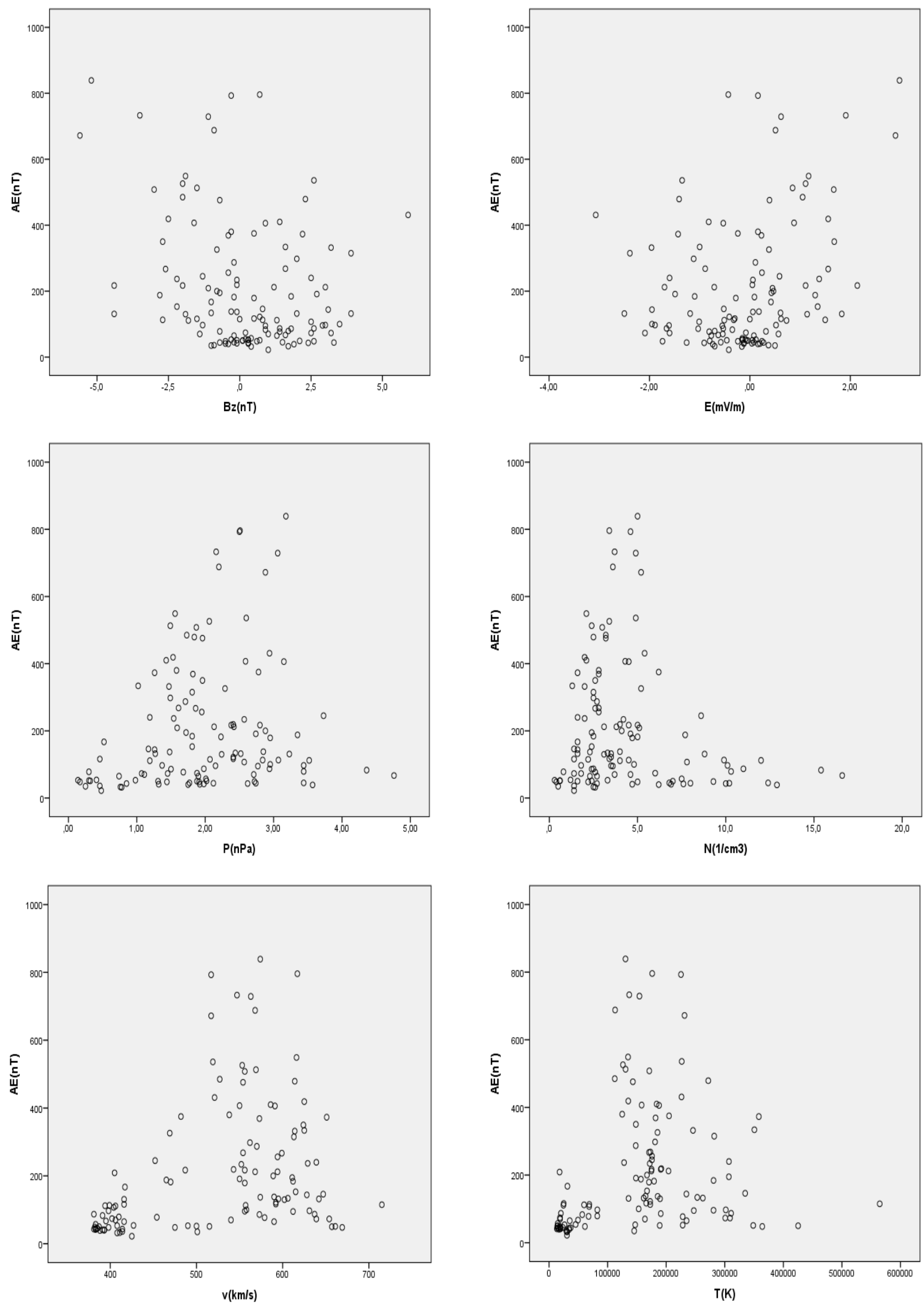

Figure 4c. Scattering of solar wind parameters $B_{z}, E, P, N, v, T$ vs. AE. 
Looking at Table 7-12 gives the reader an idea of the linear correlation among zonal indices and solar parameters. The linear model analysis of the Dst index is revealed in Table 7. One may be realized that this model is significant. Table 8 displays the model of Dst index as: $\mathrm{Dst}=-(33.135)+(3.063) \mathrm{N}+(0.002) \mathrm{T}$, where determination coefficient $\mathrm{R}$ is 0.819 .

Table 7. Anova (Analysis of variance)

\begin{tabular}{lccccc}
\hline Model & Sum of Squares & df & Mean Square & F & Sig. \\
\hline Regression & 9258.365 & 2 & 4629.183 & 119.036 & .000 \\
Residual & 4550.001 & 117 & 38.889 & & \\
Total & 13808.367 & 119 & & & \\
\hline
\end{tabular}

Table 8. Regression coefficients

\begin{tabular}{lccccc}
\hline \multirow{2}{*}{ Model } & \multicolumn{2}{c}{$\begin{array}{c}\text { Unstandardized } \\
\text { Coefficients }\end{array}$} & $\begin{array}{c}\text { Standardized } \\
\text { Coefficients }\end{array}$ & \multirow{2}{*}{$\mathrm{t}$} & \multirow{2}{*}{ Sig. } \\
\cline { 2 - 4 } & $\mathrm{B}$ & Std. Error & Beta & & \\
\hline (Constant) & -33.135 & 1.652 & & -20.060 & .000 \\
$\mathrm{~N}\left(1 / \mathrm{cm}^{3}\right)$ & 3.063 & .205 & .892 & 14.968 & .000 \\
$\mathrm{~T}(\mathrm{~K})$ & $2,12 \times 10^{-5}$ & .000 & .208 & 3.485 & .001 \\
\hline
\end{tabular}

Table 9 indicates that the model is significant, while Table 10 shows that the ap index is: $\mathrm{ap}=(2.615)+(8.459) \mathrm{P}-(2.214) \mathrm{N}$, where $\mathrm{R}$ is 0.634 .

Table 9. Anova (Analysis of variance)

\begin{tabular}{lccccc}
\hline Model & $\begin{array}{c}\text { Sum of } \\
\text { Squares }\end{array}$ & df & Mean Square & F & Sig. \\
\hline Regression & 2815.879 & 2 & 1407.939 & 39.273 & .000 \\
Residual & 4194.446 & 117 & 35.850 & & \\
Total & 7010.352 & 119 & & & \\
\hline
\end{tabular}

Table 10. Regression coefficients

\begin{tabular}{|c|c|c|c|c|c|}
\hline \multirow[t]{2}{*}{ Model } & \multicolumn{2}{|c|}{$\begin{array}{l}\text { Unstandardized } \\
\text { Coefficients }\end{array}$} & \multirow{2}{*}{$\begin{array}{c}\text { Standardized } \\
\text { Coefficients } \\
\text { Beta }\end{array}$} & \multirow[t]{2}{*}{$\mathrm{t}$} & \multirow[t]{2}{*}{ Sig. } \\
\hline & $\mathrm{B}$ & Std. Error & & & \\
\hline (Constant) & 2.615 & 1.351 & & 1.935 & .055 \\
\hline $\mathrm{P}(\mathrm{nPa})$ & 8.459 & .971 & 1.004 & 8.708 & .000 \\
\hline $\mathrm{N}\left(1 / \mathrm{cm}^{3}\right)$ & -2.214 & .282 & -.905 & -7.853 & .000 \\
\hline
\end{tabular}

Table 11 displays that the model is significant, while Table 12 indicates that the AE index is: 
$A E=(89.878)+(50.121) E+(163.936) P-(46.607) N$, where $R$ is 0.587.

Table 11. Anova (Analysis of variance)

\begin{tabular}{lccccc}
\hline Model & $\begin{array}{c}\text { Sum of } \\
\text { Squares }\end{array}$ & df & Mean Square & F & Sig. \\
\hline Regression & 1541493.876 & 2 & 513831.292 & 20.317 & .000 \\
Residual & 2933737.991 & 117 & 25290.845 & & \\
Total & 4475231.867 & 119 & & & \\
\hline
\end{tabular}

Table 12. Regression coefficients

\begin{tabular}{|c|c|c|c|c|c|}
\hline \multirow[t]{2}{*}{ Model } & \multicolumn{2}{|c|}{$\begin{array}{l}\text { Unstandardized } \\
\text { Coefficients }\end{array}$} & \multirow{2}{*}{$\begin{array}{c}\text { Standardized } \\
\text { Coefficients } \\
\text { Beta }\end{array}$} & \multirow[t]{2}{*}{$\mathrm{t}$} & \multirow[t]{2}{*}{ Sig. } \\
\hline & $\mathrm{B}$ & Std. Error & & & \\
\hline (Constant) & 89.878 & 36.075 & & 2.491 & .014 \\
\hline $\mathrm{E}(\mathrm{mV} / \mathrm{m})$ & 50.121 & 13.401 & .282 & 3.740 & .000 \\
\hline $\mathrm{P}(\mathrm{nPa})$ & 163.936 & 25.849 & .768 & 6.321 & .000 \\
\hline $\mathrm{N}\left(1 / \mathrm{cm}^{3}\right)$ & -46.607 & 7.494 & -.754 & -6.219 & .000 \\
\hline
\end{tabular}

The solar wind (v), which retracts and slows down relatively before a storm, suppresses dynamic pressure $(\mathrm{P})$, causing a serious denseness. The fluctuation in the magnetic field affects the proton density $(\mathrm{P})$ linearly $[2,31]$. The fluctuation in the magnetic field fills the coronal spaces with CME's burst and creates magnetic disturbance $[4,16]$. The correlation between Dst, ap, $\mathrm{AE}$ indices and $\mathrm{Bz}$ are displayed in Figure 5 and Table 13. The linear and nonlinear relationships between the magnetic field component $\mathrm{Bz}$ and Dst, ap, AE may be displayed in Table 13 and Figure 5. If only to mention linear models, Dst $=-(16.873)+(0.719) \mathrm{B}_{\mathrm{z}}$, where $\mathrm{R}$ is 0.133 , ap $=-(10.068)+(0.659) \mathrm{B}_{\mathrm{z}}$ where $\mathrm{R}$ is 0.170 and $\mathrm{AE}=-(30.529)+$ $(214.673) B_{z}$, where $\mathrm{R}$ is 0.313 .
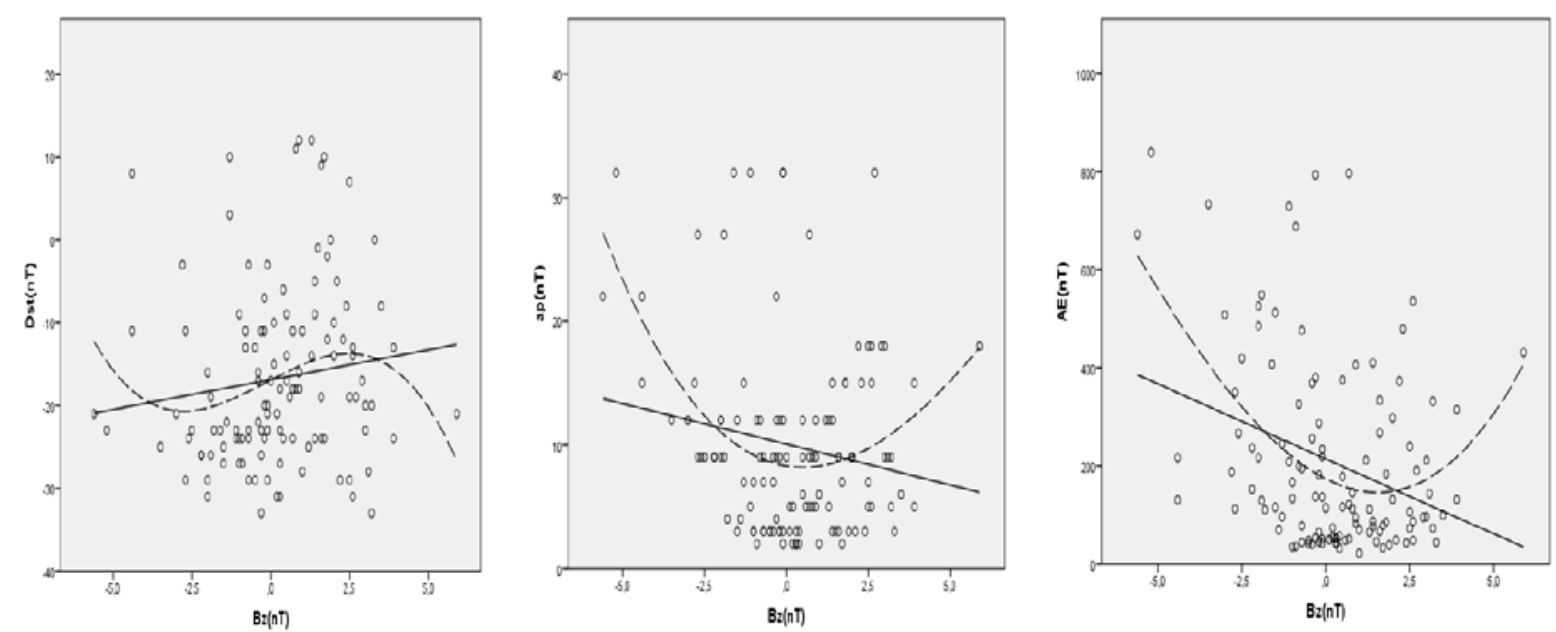

Figure 5. Linear and quadratic relation of Dst and $B_{z}$ 
Table 13. Regression coefficients and analysis of variance of Dst, ap and AE, respectively

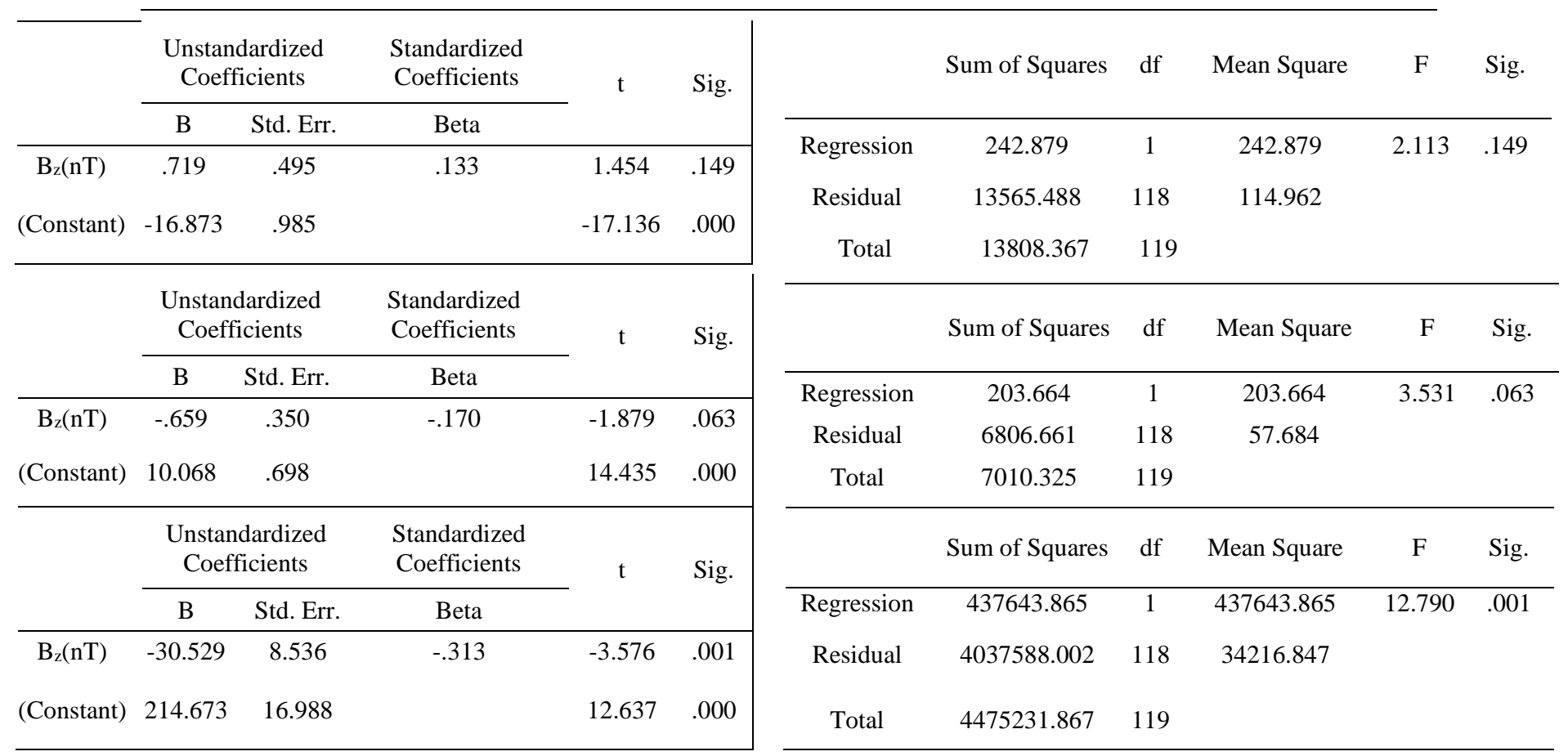

Although the plasma flow speed is seen as an adjustment for the dynamic pressure [7], it is the necessary estimation instrument of the Dst index with together the magnetic field and proton density. Physically, coronal holes created with the lack of hot electrons are the source of the high-speed solar wind streams. The magnetic field polarity is exuded by the data of the solar wind speed [1,32]. Nonlinear fluctuations in the high-speed solar wind, as well as the negative decreases in the magnetic field $\mathrm{B}_{\mathrm{z}}$ component, are vital for geomagnetic activity. The nonlinear action in the flow speed and $\mathrm{B}_{\mathrm{z}}$ component indicates coming the peak time of the Dst index. At the beginning of a geomagnetic storm, the proton density increases and affects the magnetosphere. High-density plasma pressure with low speed compresses the magnetosphere [32]. That means the storm has started for the magnetosphere-ionosphere driven by the solar wind [5-6]. As this compression and disturbance are demonstrated by Dst index, researchers are trying to increase the Dst prediction values by the coupling functions which are shaped by the solar wind parameters where the speed parameter [5] is ineluctable $[17,18]$.

High-density plasma pressure compressing the magnetosphere can be discussed in the same model as the ap index [12,13,22]. The model which is proven consistency is composed of dynamic pressure, proton density and ap index. The model containing $\mathrm{P}, \mathrm{N}$ and ap can be seen in Tables 14 and 15. The nonlinear model is $\mathrm{P}=a+b$ lnap $+c \mathrm{~N}$, where a, b, c are constants. The variance values of the model are displayed in Table 14. Analysis of dynamic pressure (P) variance values are shown in Table 14. The coefficients are $a=-0.224$ and $b=0.572, c=0.247$. Table 15 shows that all parameter estimates are within the $95 \%$ confidence interval. The model explaining this storm with $\mathbf{8 4 . 5 \%}$ accuracy is

$$
\mathrm{P}=-(0.224)+(0.572) \ln a \mathrm{p}+(0.547) \mathrm{N}
$$

This consistent $[12,13,22]$ formula is a high accuracy formula of $84 \%$ of the event. This model, especially shaped by dynamic pressure and proton density, is like a brief summary of the event. 
Table 14. Anova (Analysis of variance)

\begin{tabular}{cccc}
\hline Source & Sum of Squares & df & Mean Squares \\
\hline Regression & 557.621 & 3 & 185.874 \\
Residual & 15.312 & 117 & .131 \\
Uncorrected Total & 572.933 & 120 & \\
Corrected Total & 93.755 & 119 & \\
\hline
\end{tabular}

Table 15. Parameter estimates

\begin{tabular}{ccccc}
\hline & & & \multicolumn{2}{c}{ 95\% Confidence Interval } \\
\cline { 3 - 5 } Parameter & Estimate & Std. Error & Lower Bound Upper Bound \\
\hline a & -.224 & .109 & -.441 & -.008 \\
b & .572 & .043 & .468 & .658 \\
c & .247 & .011 & .226 & .268 \\
\hline
\end{tabular}

In the last part of the paper, it is useful to discuss the TEC values. Although the time period for analyzing anomalies in TEC values is generally before and after 15 days from the event, the author performs a review by looking at \pm 2 days to identify clearly the weak storm effect in the ionosphere. In the discussion, the upper and lower limits are calculated using (4) and (5) equations.

$$
\begin{aligned}
& U B=\mu+2 \sigma \\
& L B=\mu-2 \sigma
\end{aligned}
$$

$U B, L B, \mu$ and $\sigma$ denote upper bound, lower bound, mean and standard deviation of TEC value for each hour, respectively [35].

As a result of the examination of TEC values between 19 July-23 July, +0.83 TECU, +1.83 TECU, +0.69 TECU, +2.68 TECU, +3.74 TECU anomalies are observed respectively (total: 9.77 TECU). To understand the origin of these anomalies, looking at the irregularity in the TEC data of the weak storm (-30 nT) on August 04 may end the discussion. In the weak August storm, the total anomaly is presented to the reader as +9.25 TECU as in July. Therefore, it can be said that the storm causes these anomalies.

\section{Conclusion}

The paper traditionally analyzes the weak geomagnetic storm on July 21, 2017. In this work, descriptive analysis, correlation matrix, and dendrogram of solar wind parameters and zonal geomagnetic indices are discussed. Variables are divided into subgroups with maximum contribution principle and models of variables that can direct the phenomenon are introduced to the reader. The models reveal the physical background of the event by obeying to the causeeffect relationship. All results are in the 95\% confidence interval. The July (weak) storm exhibits similar behaviors same as moderate and intense storms. Although the response time is very short, this similarity is quite striking. Besides these discussions, the author tries to understand the contribution of electrons to the storm process by including TEC data among the 
variables. While solar wind parameters and zonal geomagnetic indices act as a family, electrons do not include in any model. Although the author repeats the calculations considering that he made a mistake, TEC data prefer to be excluded. The above-mentioned relations and models of solar parameters and zonal geomagnetic indices are visualized by graphics and tables.

\section{Acknowledgements}

I thank the NASA, Kyoto (University) World Data Center, National Geophysical Data Center. I thank Professor Giovanni Occhipinti for very supportive corrections.

\section{References}

[1] Adhikari, B., Adhikari, N., Aryal, B., Chapagain, N.P., Horvath, I., "Impacts on Proton Fluxes Observed During Different Interplanetary Conditions”, Solar Physics 294 (2019) : 61.

[2] Agopyan, H., "Istanbul iyonoküresinde ölçülen şiddetli manyetik firtına etkilerine jeofizikten bir örnek”, Tubav Bilim Dergisi 3 (4) (2010) 315-322 (in Turkish).

[3] Akasofu, S.I., "The development of the auroral substorm”, Planet. Space Sci., 12 (4) (1964) : 273-282.

[4] Ayush, S., Adhikari, B., Mishra, R.K., "Variation of Solar Wind Parameters During Intense Geomagnetic Storms”, Himalayan Physics 6-7 (2017) : 80-85.

[5] Borovsky, J.E., "The velocity and magnetic field fluctuations of the solar wind at $1 \mathrm{AU}$ : Statistical analysis of Fourier spectra and correlations with plasma properties”, Journal of Geophysical Research: Space Physics 117 (A5) (2012) : A05104.

[6] Borovsky, J.E. and Yakymenko, K., "Systems science of the magnetosphere: Creating indices of substorm activity, of the substorm-injected electron population, and of the electron radiation belt”, Journal of Geophysical Research: Space Physics 122 (10) (2017) : 10012-10035, doi:10.1002/2017JA024250.

[7] Burton R. K., McPherron R. L., Russell C. T., “An empirical relationship between interplanetary conditions and Dst”, Journal of Geophysical Research 80 (31) (1975) : 4204-4214.

[8] Elliott, H.A., Jahn, J.M, David, J.M.C., “The Kp index and solar wind speed relationship: Insights for improving space weather forecasts”, Space Weather 11 (6) (2013) : 339.

[9] Eroglu, E., "Dalga kılavuzları boyunca geçici sinyallerin transferi”, Ph.D. Thesis, Gebze High Technology Institute, 2011.

[10] Eroglu, E., Aksoy, S., Tretyakov, O.A., "Surplus of energy for time-domain waveguide modes”, Energy Educ. Sci. Tech. 29 (1) (2012) : 495.

[11] Eroglu, E., Ak, N., Koklu, K., Ozdemir, Z., Celik, N., Eren, N., "Special functions in transferring of energy; a special case: “Airy function””, Energy Educ. Sci. Tech 30 (1) (2012) : 719.

[12] Eroglu, E., "Mathematical modeling of the moderate storm on 28 February 2008", New Astronomy 60 (2018) : 33-41. 
[13] Eroglu, E., "Modeling the superstorm in the 24th solar cycle”, Earth Planets Spaces 71 26 (2019), doi: https://doi.org/10.1186/s40623-019-1002-1.

[14] Fu, H.S., Tu, J., Song, P., Cao, B. Reinisch, B.W., Yang, B., "The nightside-to-dayside evolution of the inner magnetosphere: Imager for Magnetopause-to-Aurora Global Exploration Radio Plasma Imager observations”, Journal of Geophysical Research 115 (2010) : A04213.

[15] Fu, H.S., Cao, J.B., Cully, C.M., Khotyaintsev, Y.V., Vaivads, A., Angelopoulos, V., Zong, Q.G, Santolík, O., Macúšová, E., André, M., Liu, W.L., Lu, H.Y., Zhou, M., Huang, S.Y., Zhima, Z., "Whistler-mode waves inside flux pileup region: Structured or unstructured?”, Journal of Geophysical Research 119 (2014) : 9089.

[16] Gilmour, M., Yu, C.X., Rhodes, T.L., Peebles, W.A., "Investigation of rescaled range analysis, the Hurst exponent, and long-time correlations in plasma turbulence”, Physics of Plasmas 9 (4) (2002) : 1312.

[17] Gonzalez W.D., Tsurutani, B.T., "Criteria of interplanetary parameters causing intense magnetic storms (Dst of less than -100 nT)”, Planet Space Science 35 (9) (1987) : 11011109.

[18] Gonzalez, W.D. Tsurutani, B.T., Gonzalez, A.L.C., Smith, E.J., Tang, F., Akasofu, S.I., "Solar wind-magnetosphere coupling during intense magnetic storms (1978-1979)", Journal of Geophysical Research 94 (A7) (1989) : 8835.

[19] Gonzalez, W.D., Tsurutani, B.T., Gonzalez, A.L, "Interplanetary origin of geomagnetic storms”, Space Science Reviews 88 (1999) : 529-562.

[20] Inyurt, S., and Sekertekin, A., "Modeling and predicting seasonal ionospheric variations in Turkey using artificial neural network (ANN)”, Astrophysics and Space Science 364 (4) (2019) : 62.

[21] Inyurt, S. Peker, S. and Mekik, C., "Monitoring potential ionospheric changes caused by the Van earthquake (Mw7:2)” Annales Geophysicae, 37 (2) (2019) : 143-151.

[22] Inyurt, S., "Modeling and comparison of two geomagnetic storms" Advances in Space Research 65 (3) (2020) : 1-15.

[23] Joshi, N.C., Bankoti, N.S., Pande, S., Pande, B., Pandey, K., "Relationship between interplanetary field/plasma parameters with geomagnetic indices and their behavior during intense geomagnetic storms”, New Astronomy 16 (6) (2011) : 366-385.

[24] Kamide, Y., Baumjohann, W., Daglis, L.A., Gonzalez, W.D., Grande, M., Joselyn, J.A., McPherron, R.L., Phillips, J.L., Reeves, G.D., Rostoker, G., Shanna, A.S., Singer, H.J., Tsurutani, B.T., Vasyliuna V.M., “Current understanding of magnetic storms' Stormsubstorm relationships”, Journal of Geophysical Research 103 (A8) (1998) : 17705.

[25] Loewe C.A., Prölss, G.W., "Classification and mean behavior of magnetic storms”, Journal of Geophysical Research 102 (A7) (1997) : 14209.

[26] Manoharan, P.K., Subrahmanya, C.R., Chengalur, J.N., "Space weather and solar wind studies with OWFA", Journal of Astrophysics and Astronomy 38 (2017) : doi:10.1007/s12036-017-9435-z.

[27] Mayaud, P.N., "Derivation, meaning, and use of geomagnetic indices", Geophys. Monogr. Ser. 22 (1980) : 154.

[28] Ogilvie, K.W. and Burlaga, L.F., "Hydromagnetic shocks in the solar wind”, Solar Physics 8 (2) (1969) : 422-434. 
[29] Parker, E.N., "Dynamics of the interplanetary gas and magnetic fields”, Astrophysical Journal 128 (1958) : 664.

[30] Subrahmanya, C.R., Prasad, P., Girish, B.S., Somashekar, R., Manoharan, P.K., Mittal A.K., "The receiver system for the ooty wide field array", Journal of Astrophysics and Astronomy 38 (2017) : https://doi.org/10.1007/s12036-017-9434-0.

[31] Temerin, M. and Li, X., “Dst model for 1995-2002”, Journal of Geophysical Research 111 (A4) (2006) : doi:10.1029/2005ja011257.

[32] Tsurutani B.T., Gonzalez, W.D., Gonzalez, A.L.C., Guarnieri, F.L., Gopalswamy, N., Grande, M., Kamide Y., Kasahara, Y., Lu, G., Mann, I., McPherron, R., Soraas, F., Vasyliunas, V., "Corotating solar wind streams and recurrent geomagnetic activity: A review”, Journal of Geophysical Research: Space Physics 111 (A7) (2006) : https://doi.org/10.1029/2005JA011273.

[33] Yildirim, O., Inyurt, S. Mekik, C., "Review of variations in $\mathrm{M}_{\mathrm{w}}<7$ earthquake motions on position and TEC ( $\mathrm{M}_{\mathrm{w}}=6.5$ Aegean Sea earthquake sample)”, Natural Hazards Earth System Science 16 (2016) : 543, doi:10.5194/nhess-16-543-2016.

[34] Zic., T., Vrsnak, B., Temmer, M., "Heliospheric propagation of coronal mass ejections drag-based model fitting”, The Astrophysical Journal Supplement Series 218 (2) (2015): doi:10.1088/0067-0049/218/2/32.

[35] Zhu, F., Wu, Y., Zhou, Y., Gao, Y., “Temporal and spatial distribution of GPS-TEC anomalies prior to the strong earthquakes”, Astrophysics and Space Science 345 (2) (2013) : 239. 